\title{
Appropriate dosing of sugammadex and rocuronium for reversal of neuromuscular blockade and reparalysis
}

\author{
Yutaka Oda ${ }^{1}$ (D) \\ Received: 30 July 2020 / Accepted: 9 August 2020 / Published online: 16 August 2020 \\ C) Japanese Society of Anesthesiologists 2020
}

Keywords Pharmacodynamics $\cdot$ Pharmacokinetics $\cdot$ Reparalysis $\cdot$ Rocuronium $\cdot$ Sugammadex

Sugammadex is extensively used since its introduction to our country in 2010; however, there is a paucity of data showing its optimal dose for reversal of neuromuscular blockade, particularly shortly after administration of muscle relaxants. Either the dose of rocuronium for reparalysis after reversal by sugammadex in the immediate postoperative period has not been studied in detail. In recent issues of Journal of Anesthesia, outstanding anesthesiologists have brought us critical information regarding these issues by novel methods [1-3], which will add new aspects on the preexisting knowledge and contribute to the daily clinical practice.

\section{Dose of sugammadex for neuromuscular blockade}

According to the previous studies, sugammadex $2 \mathrm{mg} /$ $\mathrm{kg}$ was derived as adequate dose for reversal of moderate neuromuscular blockade by rocuronium and vecuronium. Pühringer et al. [4] have shown that $2 \mathrm{mg} / \mathrm{kg}$ sugammadex, administered at the reappearance of the second twitch (T2) of train-of-four (TOF), was required for prompt recovery of TOF ratio to 0.9 under neuromuscular blockade by rocuronium. In this study, the recovery time was simulated using an exponential model, with spontaneous recovery time and the dose of sugammadex as variables, and an increase of the dose of sugammadex from 2 to $4 \mathrm{mg} / \mathrm{kg}$ did not shorten the recovery time.

Duvaldestin et al. [5] suggested that sugammadex $4 \mathrm{mg}$ / $\mathrm{kg}$ was required to reverse TOF ratio to 0.9 within $2 \mathrm{~min}$ at the reappearance of $1-2$ post-tetanic counts (PTC),

Yutaka Oda

yutakaodayutaka@gmail.com

1 Department of Anesthesiology, Osaka City Juso Hospital, 2-12-27, Nonaka-kita, Yodogawa-ku, Osaka 533-0034, Japan following the same methods by Pühringer et al. [4]. In this study, however, there are large differences in the duration of anesthesia as well as in the concentration of sevoflurane at the administration of sugammadex, both of which significantly affect the level of neuromuscular blockade. This dose is frequently referred to in clinical practice. It might be explained based on the findings that sugammadex and rocuronium form a complex in a 1:1 molar ratio which corresponds to a $3.6: 1(\mathrm{mg} / \mathrm{kg})$ sugammadex:rocuronium ratio, considering their respective molecular weights [6]. A volunteer study has shown that neuromuscular blockade by rocuronium with a PTC of $1-2$ was completely reversed by sugammadex $4.0 \mathrm{mg} / \mathrm{kg}$ [7], supporting the results of those studies.

It should be noted, however, that the required dose of sugammadex largely depends on the level of neuromuscular blockade [8]. Moreover, the detailed pharmacokinetic-pharmacodynamic relationships between rocuronium and sugammadex are not counted into consideration in these reports. There have been a few reports investigating the precise potency of sugammadex for antagonizing various intensities of rocuronium-induced neuromuscular block.

Kitajima et al. [1] reported that the doses of sugammadex required for recovery of the first twitch (T1) of TOF and TOF ratio until $95 \%$ of the baseline value $\left(\mathrm{ED}_{95}\right)$ were 1.34 and $1.14 \mathrm{mg} / \mathrm{kg}$, respectively, when $\mathrm{T} 1$ was maintained at $10 \%$ of the control values by titrated continuous infusion of rocuronium. They maintained the level of neuromuscular blockade at a stable level for more than $60 \mathrm{~min}$ and then measured the individual dose-response relationships by administering sugammadex $0.2 \mathrm{mg} / \mathrm{kg}$ repeatedly. They plotted the log dose against the recovery of T1 and TOF ratio relative to the baseline, and elucidated the $\mathrm{ED}_{95} \mathrm{using}$ least-squares regression analysis. In this report, the $\mathrm{ED}_{95}$ of sugammadex for recovery of T1 was significantly larger than that for recovery of TOF ratio. Possible explanation for this 
difference by the authors is as follows. An increase in T1 represents a decrease in the occupancy rate of postsynaptic nicotinic acetylcholine receptors with rocuronium. By contrast, an increase in TOF ratio represents a decrease in the fade phenomenon with repetitive muscle contractions, and progressive reduction in the amount of presynaptic acetylcholine released from the motor nerve ending during TOF stimulation.

Despite these reports showing the potency of sugammadex, residual neuromuscular blockade with TOF ratio $<0.9$ was detected in $4.3 \%$ of patients following administration of 2.0 or $4.0 \mathrm{mg} / \mathrm{kg}$ sugammadex after surgery without the guidance of neuromuscular monitor [9]. These results emphasize the importance of neuromuscular monitoring required by the Japanese Society of Anesthesiologists as well as choosing adequate dosing of sugammadex. Iwasaki et al. [2] found that the reversal dose of sugammadex was significantly smaller in patients with neuromuscular monitoring than the dose without it in a retrospective study in 3496 patients. More than half of the patients with monitoring of neuromuscular blockade required $2-2.5 \mathrm{mg} / \mathrm{kg}$ sugammadex. On the other hand, approximately half of the patients without the monitor received $>2.5 \mathrm{mg} / \mathrm{kg}$ sugammadex.

Regarding reversal of profound neuromuscular blockade shortly after administration of rocuronium, sugammadex $16 \mathrm{mg} / \mathrm{kg}$ is considered to be a safe dose [10]. This value was obtained based on the recovery time from neuromuscular blockade produced by rocuronium $1.0-1.2 \mathrm{mg} / \mathrm{kg}$, which is above the maximum dose for tracheal intubation $(0.9 \mathrm{mg} / \mathrm{kg})$ allowed in our country. However, there are less than 2-min differences in the recovery time to TOF ratio $>0.9$ between sugammadex 8 and $16 \mathrm{mg} / \mathrm{kg}$ given $3 \mathrm{~min}$ after administration of rocuronium. Neuromuscular reversal with excessive doses of sugammadex not only results in high costs but may later interfere with the potential need to re-establish neuromuscular block with rocuronium in case of emergent reintubation, suggesting the necessity for reducing the dose of sugammadex, if possible.

One of the reasons for a small number of studies using pharmacodynamic models would be ascribed to the difficulties in producing proper model for predicting deep neuromuscular effects expressed as TOF ratio $=0$. Kashima et al. [3] found that sugammadex $600 \mathrm{mg}(8.7 \mathrm{mg} / \mathrm{kg})$ administered $27 \mathrm{~min}$ after rocuronium $50 \mathrm{mg}$ reversed deep neuromuscular blockade $(\mathrm{PTC}=0)$ to $\mathrm{TOF}$ ratio $=1.0$ within a few minutes in a patient undergoing laparoscopic surgery. They developed a pharmacokinetic-pharmacodynamic model based on a previous report by Kleijn et al. [8] with an assumption that TOF counts 0 and 1 correspond to be TOF ratio of 0 and $10 \%$ as a pharmacodynamic measure. This model satisfactorily explained the recovery of TOF with small prediction errors. They estimated that the time to recovery of TOF ratio to 0.9 was $2.8 \mathrm{~min}$ and $1.4 \mathrm{~min}$ with $8.7 \mathrm{mg} / \mathrm{kg}$ and $17.4 \mathrm{mg} / \mathrm{kg}$ sugammadex, respectively, and concluded that approximately $8.0 \mathrm{mg} / \mathrm{kg}$ sugammadex was an adequate dose for reversal from deep neuromuscular blockade with PTC 0.

\section{Dose of rocuronium for reparalysis after administration of sugammadex}

The model by Kashima et al. [3] also explained the required dose of rocuronium to provide neuromuscular blockade after reversal by sugammadex. They administered rocuronium again for tracheal intubation in the aforementioned patient $28 \mathrm{~min}$ after $600 \mathrm{mg}(8.7 \mathrm{mg} / \mathrm{kg})$ sugammadex. TOF ratio decreased only to $74 \% 2 \mathrm{~min}$ after $150 \mathrm{mg}(2.2 \mathrm{mg} / \mathrm{kg}$ ) rocuronium, and additional $50 \mathrm{mg}$ was required to decrease it to 0 . This was adequately explained by that model, where time required to decrease TOF ratio to $5 \%$ was $11 \mathrm{~min}$ and $5 \mathrm{~min}$ by rocuronium $150 \mathrm{mg}(2.2 \mathrm{mg} / \mathrm{kg})$ and $200 \mathrm{mg}(2.9 \mathrm{mg} / \mathrm{kg})$, respectively. For simple calculation, they suggested the following formula of the recommended dose of rocuronium (ROC2) for re-intubation after reversal with sugammadex:

$\operatorname{ROC} 2(\mathrm{mg} / \mathrm{kg})=\mathrm{SUG}(\mathrm{mg} / \mathrm{kg}) / 4-\mathrm{ROC} 1(\mathrm{mg} / \mathrm{kg})+0.5$

where SUG is the dose of sugammadex and ROC1 is the initial dose of rocuronium. In their case, this formula gives the dose of rocuronium $2 \mathrm{mg} / \mathrm{kg}$, which is similar to $2.2 \mathrm{mg} / \mathrm{kg}$ derived from that model. In another study in healthy volunteers, a repeated dose of $1.2 \mathrm{mg} / \mathrm{kg}$ rocuronium successfully achieved TOF ratio $0 \%$ after an initial dose of $0.6 \mathrm{mg} / \mathrm{kg}$ rocuronium followed by $4.0 \mathrm{mg} / \mathrm{kg}$ sugammadex at $1-2$ PTC [7]. For these volunteers, that formula suggests $0.9 \mathrm{mg} / \mathrm{kg}$ as a required dose of rocuronium, which seems to estimate the required dose of rocuronium well.

Iwasaki et al. [11] reported that rocuronium $0.6-1.2 \mathrm{mg} / \mathrm{kg}$ was needed to re-establish neuromuscular block $12-465 \mathrm{~min}$ after reversal by sugammadex between 1.8 and $4.3 \mathrm{mg} / \mathrm{kg}$ in 11 patients required repeat surgery. Although the initial dose of rocuronium was not reported, or neuromuscular monitoring was not used in all patients in this study, larger dose of rocuronium $(0.9-1.2 \mathrm{mg} / \mathrm{kg})$ was required if it was administered within $2 \mathrm{~h}$ after sugammadex compared with that administered more than $3 \mathrm{~h}$ after sugammadex, suggesting that the time-course of action is related to the time interval between sugammadex reversal and repeat dose of rocuronium. This is partly because a considerable amount of sugammadex remains available to reverse the second dose of rocuronium [7].

\section{Measurement of neuromuscular blockade}

Acceleromyography is a simple and reliable method for neuromuscular monitoring [12], and TOF-Watch ${ }^{\circledR}$ (MSD Corporation, Tokyo) has been extensively used for this 
purpose. It has the advantages of practicality, versatility, precision, and applicability at various muscles. Recently, a cuff pressure-based myography device $\left(\right.$ TOF-Cuff ${ }^{\circledR}$, RGB Medical Devices SA, Alfonso Gómez, Madrid, Spain) has been developed [13]. It utilizes a new and simple method of stimulation of the ulnar nerve at the upper arm by active electrodes as well as sensors incorporated into a noninvasive blood pressure cuff, and has been available since 2017 . This device does not require specific limb position or expensive components used with other monitoring systems. It is also able to be used for the lower leg, although the failure rate for a TOF measurement is higher than that measured by conventional acceleromyograph (TOF-Scan ${ }^{\circledR}$, IDMED, Marseille, France) in the upper arm [14]. Kameyama et al. [15] reported that there were no differences in the onset of rocuronium-induced neuromuscular block, time to recovery of the first PTC twitch, time to recovery of the first twitch with TOF stimulation, and time to adequate reversal with sugammadex between TOF-Cuff ${ }^{\circledR}$ and TOF-Watch ${ }^{\circledR}$. This system is expected to contribute to the prevail of routine use of perioperative neuromuscular monitoring system.

In conclusion, the dose of sugammadex should be determined based on the level of neuromuscular blockade, emphasizing the importance of neuromuscular monitoring. The required dose of rocuronium for reparalysis varies depending on the elapsed time after administration of sugammadex. A cuff pressure-based myography device without finger-tip equipment is being introduced in the clinical practice.

\section{References}

1. Kitajima O, Yamamoto M, Takagi S, Suzuki T. Potency estimation of sugammadex for the reversal of moderate rocuronium-induced neuromuscular block: a non-randomized dose-response study. J Anesth. 2020;34:348-51.

2. Iwasaki H, Kurosawa A, Iida T, Sasakawa T, Kanda H. Use of intraoperative neuromuscular monitor reduces the reversal dose of sugammadex: a single-center retrospective study. J Anesth. 2020;34:276-80.

3. Kashima Y, Masui K. Individual pharmacometric analysis for sugammadex reversal and re-administration of neuromuscular blockade. J Anesth. 2020. https://doi.org/10.1007/s00540-020-2824-5.

4. Pühringer FK, Gordon M, Demeyer I, Sparr HJ, Ingimarsson J, Klarin B, van Duijnhoven W, Heeringa M. Sugammadex rapidly reverses moderate rocuronium- or vecuronium-induced neuromuscular block during sevoflurane anaesthesia: a dose-response relationship. Br J Anaesth. 2010;105:610-9.
5. Duvaldestin P, Kuizenga K, Saldien V, Claudius C, Servin F, Klein J, Debaene B, Heeringa M. A randomized, dose-response study of sugammadex given for the reversal of deep rocuroniumor vecuronium-induced neuromuscular blockade under sevoflurane anesthesia. Anesth Analg. 2010;110:74-82.

6. Bom A, Bradley M, Cameron K, Clark JK, Van Egmond J, Feilden H, MacLean EJ, Muir AW, Palin R, Rees DC, Zhang MQ. A novel concept of reversing neuromuscular block: chemical encapsulation of rocuronium bromide by a cyclodextrin-based synthetic host. Angew Chem Int Ed Engl. 2002;41:266-70.

7. Cammu G, de Kam PJ, De Graeve K, van den Heuvel M, Suy K, Morias K, Foubert L, Grobara P, Peeters P. Repeat dosing of rocuronium $1.2 \mathrm{mg} \mathrm{kg}^{-1}$ after reversal of neuromuscular block by sugammadex $4.0 \mathrm{mg} \mathrm{kg}^{-1}$ in anaesthetized healthy volunteers: a modelling-based pilot study. Br J Anaesth. 2010;105:487-92.

8. Kleijn HJ, Zollinger DP, van den Heuvel MW, Kerbusch T. Population pharmacokinetic-pharmacodynamic analysis for sugammadex-mediated reversal of rocuronium-induced neuromuscular blockade. Br J Clin Pharmacol. 2011;72:415-33.

9. Kotake Y, Ochiai R, Suzuki T, Ogawa S, Takagi S, Ozaki M, Nakatsuka I, Takeda J. Reversal with sugammadex in the absence of monitoring did not preclude residual neuromuscular block. Anesth Analg. 2013;117:345-51.

10. Pühringer FK, Rex C, Sielenkamper AW, Claudius C, Larsen PB, Prins ME, Eikermann M, Khuenl-Brady KS. Reversal of profound, high-dose rocuronium-induced neuromuscular blockade by sugammadex at two different time points: an international, multicenter, randomized, dose-finding, safety assessor-blinded, phase II trial. Anesthesiology. 2008;109:188-97.

11. Iwasaki H, Sasakawa T, Takahoko K, Takagi S, Nakatsuka H, Suzuki T, Iwasaki H. A case series of re-establishment of neuromuscular block with rocuronium after sugammadex reversal. J Anesth. 2016;30:534-7.

12. Claudius C, Viby-Mogensen J. Acceleromyography for use in scientific and clinical practice: a systematic review of the evidence. Anesthesiology. 2008;108:1117-40.

13. Veiga Ruiz G, Garcia Cayuela J, Orozco Montes J, Parreno Caparros M, Garcia Rojo B, Aguayo Albasini JL. Monitoring intraoperative neuromuscular blockade and blood pressure with one device (TOF-Cuff): a comparative study with mechanomyography and invasive blood pressure. Rev Esp Anestesiol Reanim. 2017;64:560-7.

14. Dullenkopf A, Horn K, Steurer MP, Hess F, Welter J. Placement of TOF-Cuff(R) on the lower leg for neuromuscular and blood pressure monitoring during anesthetic induction for shoulder surgeries. J Anesth. 2020;34:79-85.

15. Kameyama Y, Takagi S, Seto K, Kajiwara I, Goto M, Kitajima O, Suzuki T. Efficiency of the TOF-Cuff for the evaluation of rocuronium-induced neuromuscular block and its reversal with sugammadex: a comparative study vs. acceleromyography. J Anesth. 2019;33:80-4.

Publisher's Note Springer Nature remains neutral with regard to jurisdictional claims in published maps and institutional affiliations. 